\title{
PSYCHE.
}

\section{NEELUS MURINUS, REPRESENTING A NEW THYSANURAN FAMILY.*}

By JUSTUS WATSON FOLSOM, CAMBRIDGE, MAss.

This species was common in a greenhouse at Cambridge in February and March of this year. It occurred only on the under side of wet stones among "filmy ferns" (Hymenophyllaceae) from Jamaica, and therefore may not be indigenous.

Neelus murinus is evidently nearly related to the Papiriidae and Smynthuridae, especially the latter, but differs in important respects. The antennae closely resemble those of certain Smynthuri having an unringed terminal segment; the superior claw is unidentate, an apparently constant Smynthuran characteristic, as observed by $\mathrm{Mr}$. MacGillivray; and an approach to a horizontal head is seen in $S$. marginatus Schött. $\dagger$ On the other hand, as I have not yet been able to find any tracheae, Neelus may, like Papirius, have none. The pseudonychia resemble those of Tomocerus and the tubercles of the ventral tube are similar to those of Tomocerus, Orchesella and other genera.

* Contributions from the Zoölogical Laboratory of the Museum of Comparative Zoölogy, under the direction of E. L. Mark, No. LX.

† Schött, Harald. Zur Systematik und Verbreitung Palaearctischer Collembola. Kongl. Sven. Vet. Akad. Handl. Bd. 25, No. II p. 25, Pl. I. fig. I1. 1893 .
We may present as follows the generic characters of Neelus as contrasted with those of Smynthurus and Papirius.

$\ddagger$ Neelus, n. gen.

Head horizontal, broadly articulated. Thorax longer than abdomen. Anal tubercle inconspicuous. Ventral filaments represented by two rounded tubercles. Superior claw pseudonychiate. Dentes ventrally toothed, apically two lobed. Eyes absent. Tracheae apparently absent.

Neelidfae, n. fam.

The following characters may collectively be considered of family value as distinguished from those of Smynthuridae and Papiriidae. Head horizontal. Thorax exceeding abdomen. Processes of ventral tube tuberculate. Tracheae apparently wanting. Eyes absent.

I am glad to take this opportunity to thank Professor Mark, of Harvard University, for the valuable supervision he has given me while studying this species.

Neelus murinus n. sp. (Plate 8),-General color ochraceous-buff, in alcoholic specimens ochraceous-orange; when young, white with a dorsal longitudinal median ill-defined

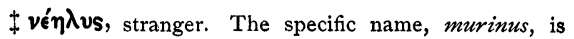
based upon the fancied resemblance to a mouse. 
buff stripe; head paler; antennae, legs and furcula white. Head horizontal (fig. 5), in lateral. view ovate, half as long as body, smooth, anteriorly with short setae. Eyes absent. Antennae (fig. 7) shorter than the width of the head, not geniculate, slender, segments four, their relative lengths as I $: 3: 4: 5$; basal segment globose, naked; second subcylindrical, sparsely hairy apically; third cylindrical, subpetiolate, more hairy; terminal segment long-conical, with hairs curving towards the notched apex. Labrum and labium projecting, with stout setae. Mandibles with long, falcate-oblong apex (fig. I); terminal tooth long, sinuate within; lower incisive teeth small, three and four, compressed; below the base of the apex is a prominent rounded lobe directed forward; molar surface little convex, minutely denticulate, bounded on one side by a longitudinal row of four or three large, blunt teeth, respectively dorsal and ventral on the right and left mandibles; molar surface with a slight posterior lobe. Maxillae (fig. 3 ) with a conspicuous, dorso-external, curved, acuminate claw; ventral and internal to this, a wavy, linear process bearing on distal half an external comb of long teeth; remainder of maxilla composed of two large, oblong, concaved appendages, each with four or five ribs terminating in as many teeth on the anterior truncated margin. Body (fig. 5) seen from above oval, smooth; in profile with higharched dorsal outline; smooth excepting a few bristles on the inconspicuous anal tubercle. Prothorax compressed, broadly articulated with the head. Ventral surface white, much swollen before the manubrium. Ventral tube (figs. 5 and 6 ) equal to dentes in length, cylindrical, crenate anteriorly, one-lobed posteriorly near base, ending in two semi-globose papillate tubercles. Legs slender, about as long as furcula, scarcely bristly except on tibia. Superior claw (fig. 2) as long as third antennal segment, slender, internally sinuate with one sharp tooth one-third from apex; a linear pseudonychium, as long as the inferior claw, arises from either side the base of the external margin of superior claw (fig. 8). Inferior claw less than half the other in length, uniformly tapering, scarcely curving with the superior claw, smooth, not toothed; tenent hairs absent. Furcula short, scarcely reaching mesothorax; segments ventrally as I : I.5: I ; manubrium stout, swollen, with a few ventral hairs and sinuate distal articulation; dentes laterally a little tapering, distally (fig. 9) with five large, lateral teeth at intervals, three being external, and two internal, also a long subapical ventral bristle and an evident, blunt-conical, apical lobe on either side the base of the mucro; mucrones laterally narrowly lanceolate (fig. 4), deeply concave ventrally with each edge distinctly serrate and with simple apex.

Maximum length, $0.7 \mathrm{~mm}$. Described from over fifty types, twenty-five of which have been given to the Museum of Comparative Zoölogy at Cambridge, Mass.

\section{EXPLANATION OF PLATE 8.}

Neelus murinus, n. sp.

Fig. I. Extremity of right mandible, from above, $x 530$.

Fig. 2. Tarsus and claws of one foot, $\mathrm{x} 530$.

Fig. 3. Extremity of right maxilla, from above, $x 530$.

Fig. 4. Side view of mucro and end of dens, $x$ 440,

Fig. 5. Left side of insect, ventral tube turned backward, $\mathbf{x} 72$.

Fig. 6. Ventral tube, $\mathrm{x}$ II6.

Fig. 7. Antenna, $x$ 440.

Fig. 8. Outside of superior claw to show pseudonychia, $x$ 530.

Fig. 9. Dorso-lateral view of right mucro and part of dens, $\times 440$. 
Psyche, Vol. 7, 1896.

Plate 8.

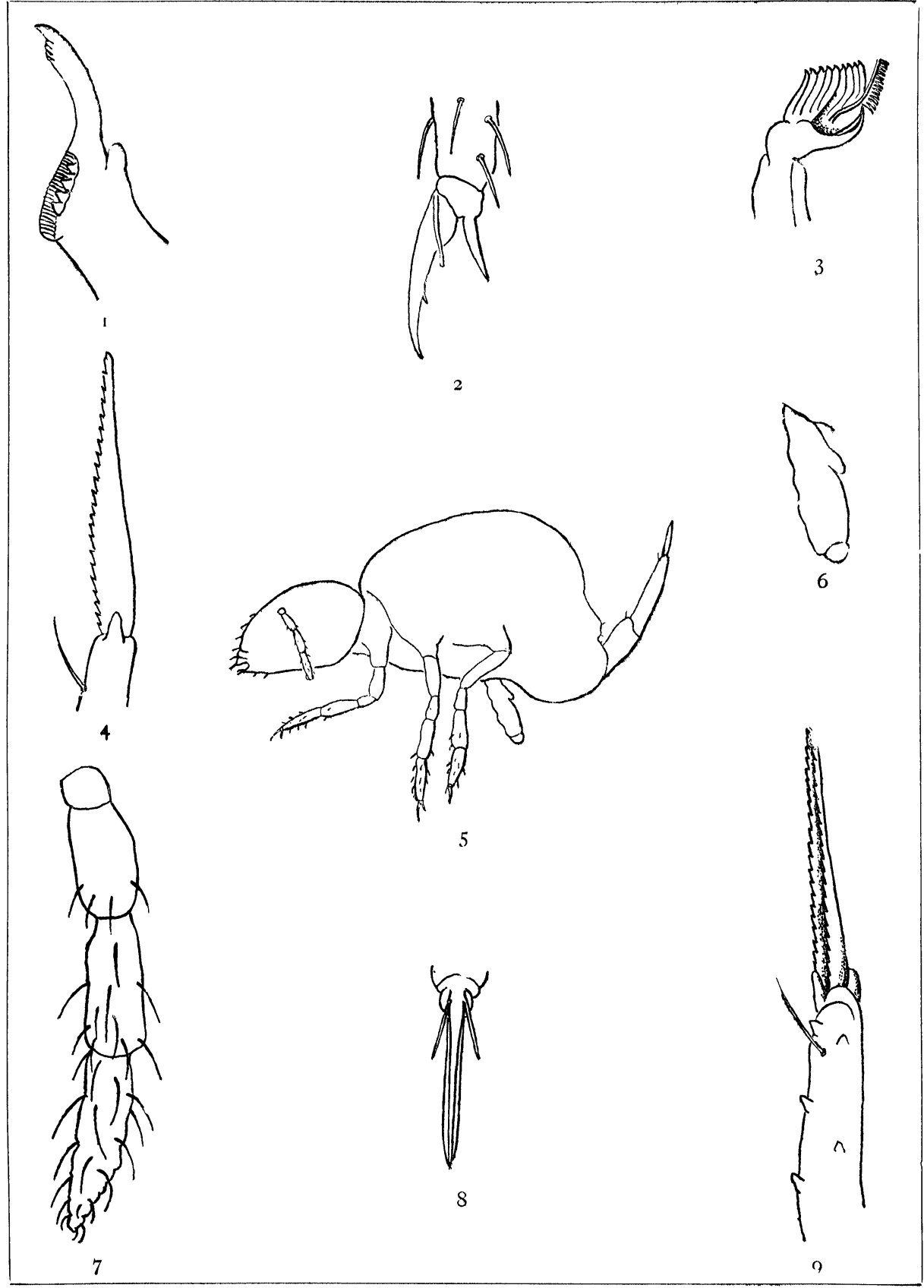

J. W. Folsom, Del.

FOLSOM, NEELUS. 

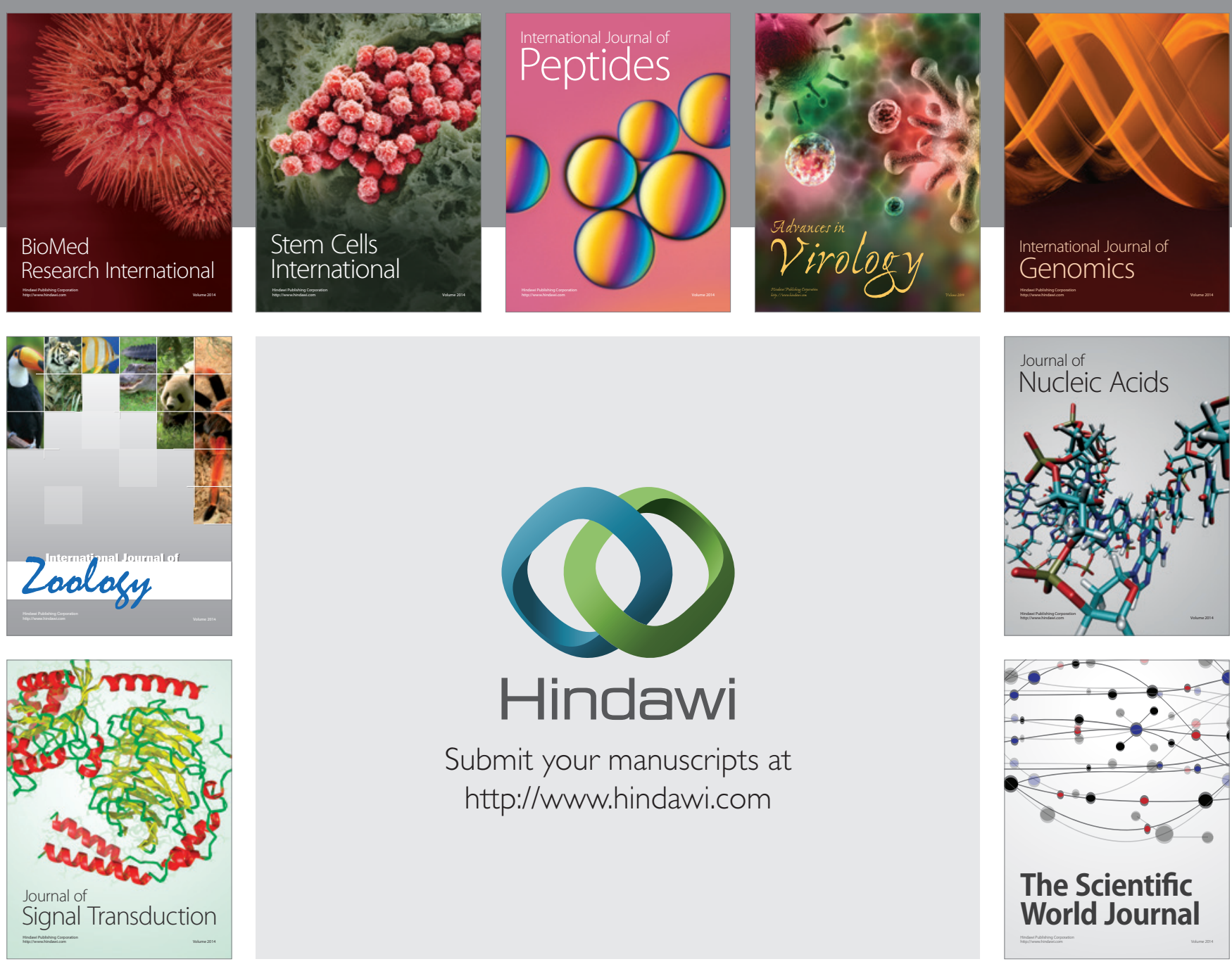

Submit your manuscripts at

http://www.hindawi.com
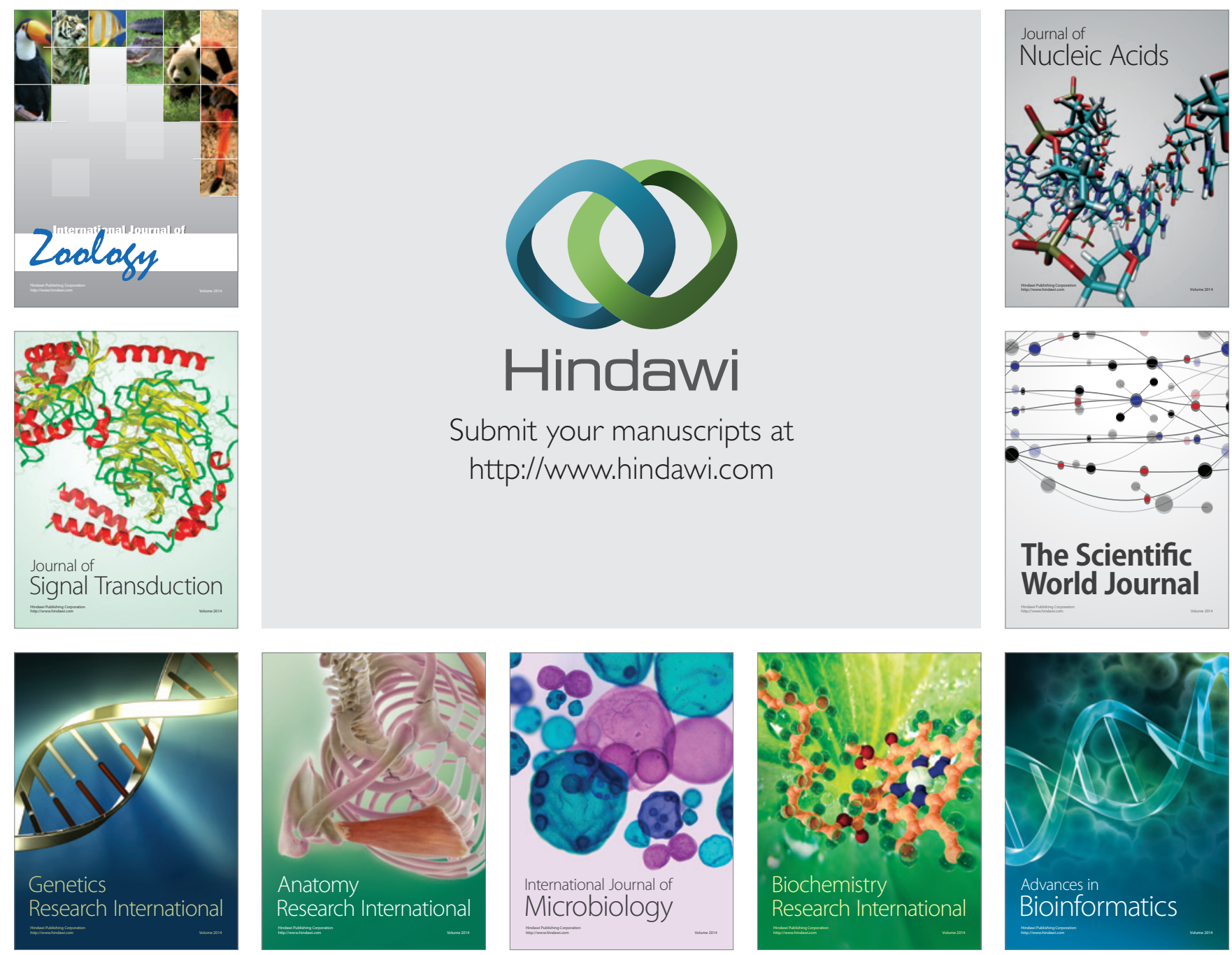

The Scientific World Journal
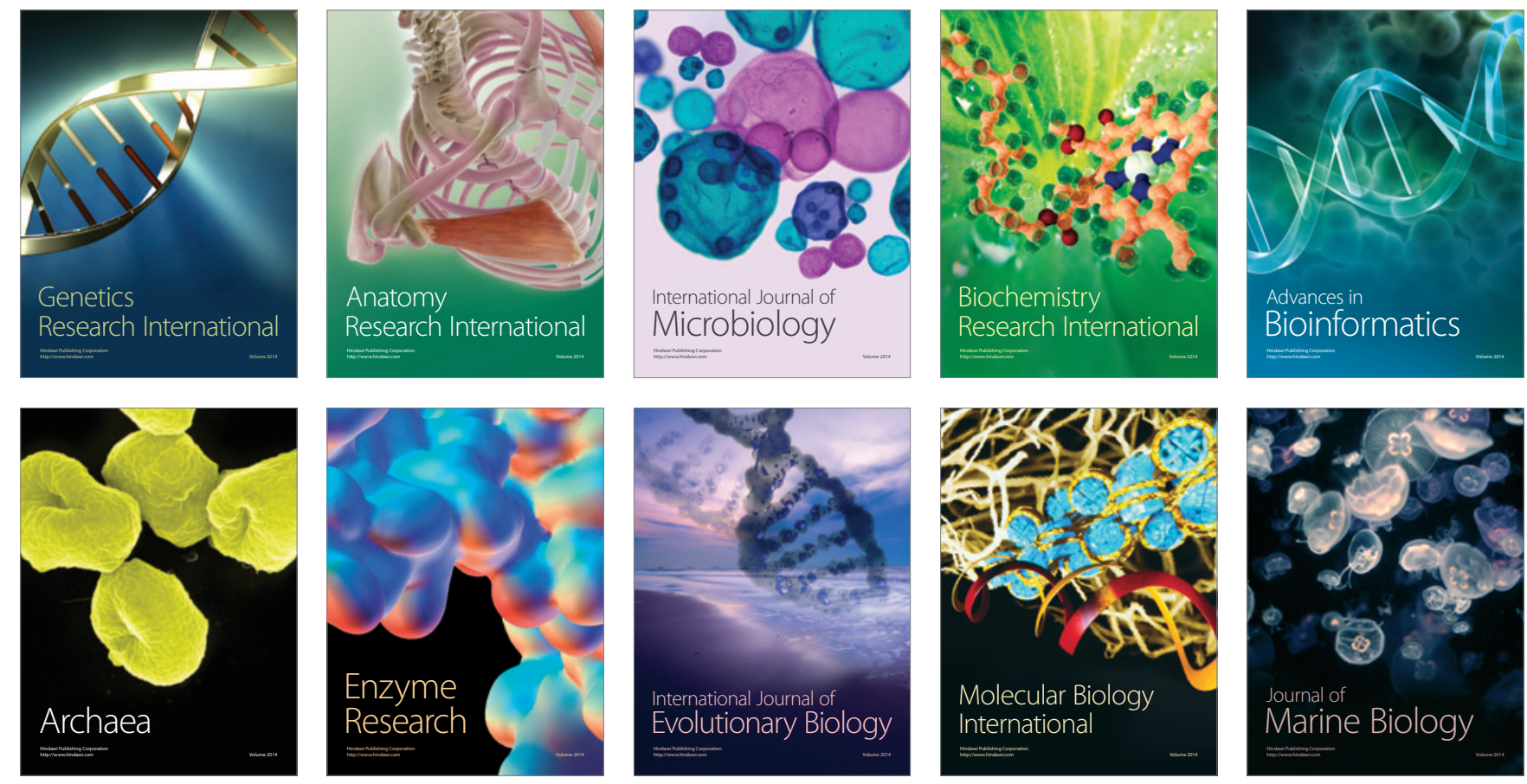